\title{
Monitoring of water surface temperature of Eurasian large lakes using MODIS LST product
}

\author{
Jia $\mathrm{Du}^{1}$, Pierre Jacinthe ${ }^{2}$, Haohao Zhou ${ }^{3}$, Xiaoyun Xiang ${ }^{4}$, Boyu Zhao ${ }^{1}$, Min Wang ${ }^{1}$, and \\ Kaishan Song ${ }^{1}$ \\ ${ }^{1}$ Northeast Institute of Geography and Agroecology Chinese Academy of Sciences \\ ${ }^{2}$ Indiana University Purdue University at Indianapolis \\ ${ }^{3}$ Yanbian University \\ ${ }^{4}$ Jilin Normal University
}

May 5, 2020

\begin{abstract}
In this study, data from MODIS land surface temperature product level 3 (MOD11A2) were used to investigate the spatiotemporal variation of Eurasian lakes water surface temperature (LWST) from 2001 to 2015, and to examine the most influencing factors of that variation. The temperature of most lakes in the dry climate zone and in the equatorial climatic zone varied from 17 to $31^{\circ} \mathrm{C}$ and from 23 to $27^{\circ} \mathrm{C}$, respectively. LWSTs in the warm temperate and cold climatic zones were in the range of 20 to $27^{\circ} \mathrm{C}$ and -0.6 and $17{ }^{\circ} \mathrm{C}$, respectively. The average daytime LWST in the polar climate zone was $-0.71^{\circ} \mathrm{C}$ in the summer. Lakes in high latitude and in the Tibetan Plateau displayed low LWST, ranging from $-11^{\circ} \mathrm{C}$ to $26^{\circ} \mathrm{C}$ during the nighttime. Large spatial variations of diurnal temperature difference (DTD) was observed in lakes across Eurasia. However, variations in DTDs were small in lakes located in high latitude and in tropical rainforest regions. The shallow lakes showed a rapid response of LWST to solar and atmospheric forcing, while in the large and deep lakes, that response was sluggish. Results of this study demonstrated the applicability of remote sensing and MODIS LST products to capture the spatial-temporal variability of LWST across continental scales, in particular for the vast wilderness areas and protected environment in high latitude regions of the world. The approach can be used in future studies examining processes and factors controlling large scale variability of LWST.
\end{abstract}

\section{Data Availability Statement}

Supporting data for this study are openly available in MOD11A2 MODIS/Terra Land Surface Temperature and the Emissivity 8-Day L3 Global 1km SIN Grid athttp://doi.org/10.5067/MODIS/MOD11A2.006, reference number (NASA LP DAAC, 2019) and MYD11B2 MODIS/Aqua Land Surface Temperature and the Emissivity 8-day L3 Global 6km SIN Grid athttp://doi.org/10.5067/MODIS/MYD11B2.006, reference number (NASA LP DAAC, 2019)

\section{Introduction}

Water temperature of inland water bodies is a critical parameter that governs an array of aquatic ecosystem functions that involve physical, chemical, and biological processes (Li, Chen, \& Zhang, 2015; Ma et al., 2016). Inland water temperature is regulated by multiple interacting factors, and excessive lake water warming has severe ecological consequences (Winslow, Read, Hansen, Rose, \& Robertson, 2017; Kraemer, Mehner, \& Adrian, 2017). Adrian et al. reported that some of the largest lakes across the world have shown notable temperature increases due to climate change (Adrian et al., 2009; Schmidt et al., 2018). For example, the temperature of Lake Baikal (Russia) has increased by approximately $1.2{ }^{\circ} \mathrm{C}$ since 1946 (Dörnhöfer \& Oppelt, 
2016). Lake temperature reflects its morphology, watershed conditions and hydrological dynamics, and variably influences the biology of resident aquatic organisms (Wetzel, 2001; Parastatidis, Mitraka, Chrysoulakis, \& Abrams, 2017; Song et al., 2016). Conventional approaches for measuring lake water temperature using in situ sensors and data loggers provide information that is temporally continuous but spatially limited. These limitations therefore hinders widespread application of conventional approaches for capturing temperature variation at large spatial scales (Parastatidis et al., 2017). Yet, synoptic information is needed to capture thermal heterogeneity in large lakes, examine patterns of thermal variation, and explain fundamental biophysical and chemical processes in these water bodies (Hook, Vaughan, Tonooka, \& Schladow, 2007; Ke \& Song, 2014).

Water temperature of lakes is primarily influenced by their absorption of solar energy in a process affected by an array of physical, chemical and hydro-morphologic properties of lake ecosystems (Li et al., 2015; Woolway et al., 2018). In this respect, the surface temperature of lake water is highly dynamic, as it changes seasonally and diurnally due to variation in air temperature and the insulation effect of snow/ice (Li et al., 2015; Parastatidis et al., 2017; Song et al., 2016; Zhang et al., 2014). The amount of sunlight absorbed by water increases exponentially with the distance it travels through the water column, particularly for radiation wavelengths shorter than $750 \mathrm{~nm}$ (Schmidt et al., 2018; Song et al., 2016). The high specific heat of water enables the dissipation of light energy and its accumulation as heat in the water column. However, retention of that energy depends on multiple factors (wind speed, currents and other water movements, watershed geomorphology) influencing its distribution within a lake system, and the change rate between water input and discharge through the tributaries (Gorham, 1964). Thus, the pattern of thermal evolution and stratification influences fundamentally the cycling of physical and chemical components of lakes, which in turn drives primary productivity and decomposition processes (Wetzel, 2001).

Thermal remote sensing methods for monitoring lake water surface temperature (LWST) circumvent problems of accessibility to lakes in remote areas and so provide a synoptic context for evaluating relationships between landscape features and water thermal characteristics(Kraemer et al., 2017; Moukomla \& Blanken., 2016; Zhong, Notaro, \& Vavrus, 2018). Thermal infrared (TIR) remote sensing can reliably map LWST and its circulation patterns in lakes using various satellite sensors (Ke \& Song, 2014). Of those, the Advanced Very High Resolution Radiometer (AVHRR) and Moderate Resolution Imaging Spectroradiometer (MODIS) on board Terra/Aqua have been widely used for monitoring lake surface temperatures (Zhang et al., 2014; Phillips, Saylor, Kaye, \& Gibert, 2016). Landsat-Thematic Mapper(TM)/ Enhanced Thematic Mapper Plus (ETM+)/Operational Land Imager (OLI) and Advanced Spaceborne Thermal Emission and Reflection Radiometer (ASTER) data are commonly used to retrieve thermal features of inland and coastal waters (Kraemer et al., 2017; Trumpickas, Shuter, Minns, \& Cyr, 2015).

Although LWST studies have been conducted at various scales around the world, the distribution pattern of LWST for Eurasia lakes has yet to be analyzed. Investigations about the relationship between LWST and factors regulating its spatiotemporal variations have been reported (Kraemer et al., 2017; Parastatidis et al., 2017; Trumpickas et al., 2015). The overall distribution pattern of LWST for Eurasia lakes deserves investigation (Zhang, Xie, Kang, Yi, \& Ackley, 2011; Yuan et al., 2015).

In this study, 3,840 composites of MODIS imagery data covering the terrestrial area of Eurasia were processed and analyzed. The characteristics of LWST for 1,098 lakes that are at least $25 \mathrm{~km}^{2}$ in size were examined to determine spatial associations with climatic, landscape and hydrologic conditions. The objectives of this study were to (1) examine LWST variation of lakes at the Eurasian continental scale based on time-series MODIS LST data for the period 2001-2015; (2) examine intra-annual rates of temperature change of some typical large lakes in Eurasia; and (3) evaluate potential factors that contribute to variations in LWST.

\title{
2. Materials and Methods
}

\author{
2.1 Criteria of lakes selection
}


In the pre-satellite remote sensing stage, three types of independent approaches were generally used to obtain a global lake census: (1) a lake-type approach based on the origin of lakes, (2) an extrapolation of known regional censuses, and (3) a climatic approach based on lake distribution in homogeneous temperature and runoff environments (Meybeck, 2011). With respect to the last approach, it links lake distribution with five major climatic biomes, i.e., deglaciated regions (52\%), temperate regions (13\%), dry and arid regions $(25 \%)$, deserts $(1 \%)$, and wet tropics $(9 \%)$. This approach has clear merits in combining temperature and surface-water runoff (Wetzel, 2001).

With the advent of satellite remote sensing, a global census of lake distribution and thermal characterization has become possible (Downing et al., 2006). Using MODIS LST products at a nominal spatial resolution of $1 \mathrm{~km}^{2}$, this study extracted lakes and water reservoirs larger than $25 \mathrm{~km}^{2}$ in Eurasia from the Global Lakes and Reservoirs Database (Lehner \& Döll, 2004); this yielded a total of 1,098 water bodies (Figure 1). Among those, 861 lakes and 237 water reservoirs were in Asia and Europe, respectively. It should be noted that some lakes or reservoirs greater than $25 \mathrm{~km}^{2}$ might not have been selected if one of their dimension is smaller than 1-km, the spatial resolution of the MODIS LST product. Such elongated water bodies would likely to be located along shorelines. The selected 1,098 lakes cover 0.63 million $\mathrm{km}^{2}$, which is about $44.3 \%$ of the world's total lake areas (Lehner \& Döll, 2004).

\section{[Insert Figure 1 about here]}

Figure 1: Location, across Eurasia, of the 1,098 lakes and reservoirs (blue) selected for the study and the climatic zones where the lakes and reservoirs are situated. Typical lakes within each climatic zone are shown in red.

\subsection{MODIS LST product preprocessing}

Daily MODIS-Terra/Aqua LST (level 2, collection 6) is an option to characterize LWST. However, in order to track thermal dynamics of water bodies, cloud contamination must be accounted for and it may cause a large proportion of invalid pixels in the MODIS data product. Therefore, MODIS LST 8-day composite product (level 3, MOD11A2), which integrates averaged daily LST observations of eight days with a nominal resolution of $1 \mathrm{~km}^{2}$, was considered suitable for this investigation. The 2015 MOD11A2 data for the Eurasian continent were downloaded from NASA's Land Processes Distributed Active Archive Center (LP-DAAC) using the Warehouse Inventory Search Tool (WIST). To track inter-annual temperature variation, 18 great lakes (Figure 1) with obvious water surface area variations in the 15-year period from 1 January 2001 to 31 December 2015 were identified. Then, the MODIS Reprojection Tool (MRT) (LP DAAC, 2001; Sioux Falls, South Dakota) was used to extract 8-day composite LST data. MODIS LST over lake surfaces was evaluated against in situ -measured temperature with absolute differences in the range of 0.8-1.9 K (O'Reilly et al., 2015). As for other lakes in China, MODIS LST products were validated with direct temperature measurements of lake waters made in 2015.

\subsection{LST data analysis}

After mosaicking using MRT, the MOD11A2 images were projected onto Albers in GeoTIFF format using nearest neighbor interpolation. The daytime LST (overpass time is circa 10:30 am local time), nighttime LST (overpass time is circa 22:30 pm local time), and corresponding quality control images (QC-daytime, QC-nighttime) were extracted. Due to the strong contrast of land and water spectral features in the near infrared (NIR) and green band, thresholding was used to extract boundaries of water bodies based on the spectral ratio of NIR/Green using Landsat OLI imagery. The shape file for water surface areas greater than $25 \mathrm{~km}^{2}$ was generated using Landsat-OLI imagery acquired in 2010, by referencing it to MODIS reflectance product (MOD09Q1) in seeking a robust-matching MODIS LST product. To minimize seasonal or inter-annual difference on Eurasian lakes measurement, the algorithm LakeTime, which is suitable for lake mapping at continental and global scales, was used to select Landsat scenes based on seasonally-defined climatic and hydrological variables (Lyons \& Sheng, 2017; Sheng et al., 2016). LakeTime is robust and reliable for delineating lake boundaries using lake-specific NDWI thresholds (Sheng et al., 2016). LakeTime can not only reduce the impacts of seasonal and inter-annual variability, but also mitigate cloud contamination effects, 
and significantly reduce labor costs in the subsequent QA/QC process (Sheng et al., 2016). To avoid possible land-water interface contamination and fluctuation in lake surface areas, a 500-m offshore buffer zone was generated to exclude LST pixels along shoreline zones (Ke \& Song, 2014). Despite using the 8-day composite product (MOD11A2), invalid pixels could still arise from cloud contamination, so additional procedures were taken to remove questionable pixels in the final MODIS LST product (Ke \& Song, 2014; Deo \& Şahin, 2017). To do this, unreliable LST pixels over lakes were removed using QC information, followed by median filtering of time-series LST data stacks (Ke \& Song, 2014). In the first step, all pixels having an average LST error of $<1 \mathrm{~K}$ (i.e., $\mathrm{QC}=0,1,5,17$, and 21) were kept, while pixels with other $\mathrm{QC}$ values were removed through referencing to LST data quality flags stored in the QC file. In the second step, a data cube was generated by stacking 46 extracted LST layers according to the Julian day sequence of the generated product, to which a median filtering algorithm iterated pixel by pixel to eliminate any questionable pixels in the LST images (Figure 2). In most cases, the 8-day composites consisted of at least $70 \%$ valid pixels. Over the 16-year study period, only 97 images (out of 3,840 images or $2.5 \%$ ) had less than $70 \%$ valid pixels. The months with affected images were consistent over the years. Most affected images were from April to June, and from September to mid-December. Furthermore, there were more valid images in the nighttime MODIS LST product (Ke \& Song, 2014). Finally, to track temporal trends in LWST for the selected lakes in Eurasia, annual rates of temperature change from MODIS LST data were regressed against the data acquisition year using linear regression (Zhang et al., 2014).

$\mathrm{y}=\mathrm{a}+\mathrm{bx}+\mathrm{e}(1)$

where y represents the MODIS LST, $\mathrm{x}$ denotes the time-series of years, e represents the residuals, $\mathrm{a}$ is the intercept, and $\mathrm{b}$ is the rate of temperature change. The coefficients $\mathrm{a}$ and $\mathrm{b}$ were determined through least squares fitting.

\section{[Insert Figure 2 about here]}

Figure 2: Flowchart of MODIS LST product processing procedure.

\subsection{Statistical analysis of LWST}

The mean LWST was obtained by averaging daytime and nighttime LST for all pixels within composited images over a specific period and for a given lake. The mean annual LWST for daytime or nighttime was computed by aggregating the 8-day LWST composite data for the corresponding year (Ke \& Song, 2014). Diurnal temperature differences (DTDs) of LWST represented the difference between daytime and nighttime temperatures. The starting point of the freeze-over month was determined by referencing to day-night averaged LWSTs of lakes $<0{ }^{\circ} \mathrm{C}$. The end of the frozen period was determined by referencing to day-night averaged LWSTs of lakes at $>0{ }^{\circ} \mathrm{C}$.

Intra-annual variation in LWST was analyzed by averaging daytime and nighttime LWST during ice-free seasons over the 16 years study period. For each year, we mapped the annual average LST that was calculated using 8-day LWST time-series on a pixel-by-pixel basis. Additionally, since ice break-up date, freeze-up date and ice-free duration are directly related to LWST, these three variables were calculated by counting the accumulated days of mean temperature (i.e., [daytime + nighttime] $/ 2$ ) above and below $0{ }^{\circ} \mathrm{C}$ for each lake; for all these calculations, the median Julian day for each 8-day composite was used.

\section{Results}

\subsection{Patterns of Eurasian lake surface temperatures}

As shown in Figure 3(a), there was a discernable contrasting pattern in the annual average daytime LWST of Eurasian lakes derived from MODIS products. Lakes with high WST were mainly distributed in the Iran Plateau, the South Asian subcontinent, the Indo-China Peninsula, and Southeast Asia. As expected, lakes at higher latitudes, especially those situated in the boreal or the Taiga biome, exhibited low WST; lakes in 
the Tibetan Plateau also featured low WST (Figure 3(a)). It should also be noted that lakes with WST in the ranges $17-23{ }^{\circ} \mathrm{C}, 23-30{ }^{\circ} \mathrm{C}$, and $>30{ }^{\circ} \mathrm{C}$ intermingled in the Indo-China Peninsula, as well in the South Asian subcontinent (Figure 3(a)). Thus, besides solar radiation and air temperature, other factors such as water depth, volume and source likely regulate the variations in LWST. With respect to nighttime MODIS measurements (range: $-11^{\circ} \mathrm{C}$ to $26{ }^{\circ} \mathrm{C}$; Figure $3(\mathrm{~b})$ ), the spatial pattern of LWST was generally similar to that of the daytime measurements. However, the pattern of nighttime LWST was more homogeneous in its distribution, more closely resembling that of air temperature at the Eurasian continental scale.

The 1,098 large Eurasian lakes examined in the present study exhibited identifiable spatial variations in their diurnal temperature difference (DTD). Evidence of a latitudinal pattern in DTD is apparent (Figure 3(c)). Lakes with larger DTDs were mainly distributed in the arid and semi-arid climatic regions (Figure 3(c)), although some lakes situated in high elevation areas also exhibited large DTDs. Careful examination of the data also revealed that large and deep lakes (e.g., Lakes Baikal, Issyk, Qinghai on the Tibetan Plateau; Table 2) showed lower DTDs compared to small and shallow lakes which exhibited large DTDs. Therefore, it may be inferred that large and deep lakes with huge water storage capacity possess more stable thermal regime and smaller DTDs.

\section{[Insert Figure 3(a,b,c) about here]}

Figure 3: The distribution of mean surface water temperature of lakes in Eurasia during the daytime (a), nighttime (b), and diurnal temperature difference (DTD) (c). Reported data are from the summer 2015.

\subsection{Inter-annual variation in lake surface temperatures}

Following the IPCC AR.5 report (IPCC, 2014) and the recommendation "to track global warming hotspots with reference to global climatic zones and corresponding lake distributions", a group of 10 typical lakes (largest lakes within a climatic zone) from Asia and 8 typical lakes from Europe (Figure 1) were selected, and analyzed with respect to inter-annual variation in LWST using MODIS LST measurements from 2001 to 2015 .

\subsubsection{Typical lakes from Asia}

The inter-annual variations in LWST for the 10 typical lakes from Asia during the period 2001-2015 are shown in Figure 4. From the annual daytime and nighttime LWST values, there was no clear trend in lake water temperature during the study period. For Lake Baikal, a slight increase in LWST was observed with both daytime and nighttime measurements (Figure 4(a)). On the Mongolia Plateau, a slight but insignificant rise in LWST was apparent for Lake Khar Us at nighttime, whereas Lake Uvs showed a slight temperature decrease, albeit not significant, over the study period (Figure 4(e) and Figure 4(b)). Likewise, for Lake Balkhash and Khanka, a slight decrease at daytime and a slight increase at nighttime were observed, but these trends were not significant (Figure 4(c) and Figure 4(f)). Situated in the Pamir, the alpine Lake Issyk underwent a rather weak temperature decline over time, but this was not a significant trend (Figure 4(d)). It is worth noting that Lake Taymyr (Figure 4(h)), did show a strong and obvious increase in temperature during the study period (2001-2015) for both daytime and nighttime measurements $(\mathrm{y}=0.19 \mathrm{x}-392.76$, $\mathrm{R}^{2}=0.51, \mathrm{P}=0.003$ for daytime; and $\mathrm{y}=0.2 \mathrm{x}-408.52, \mathrm{R}^{2}=0.44, \mathrm{P}=0.007$ for nighttime). For Lake Van and Lake Young Bhutto, a slight increase in both of daytime and nighttime temperature was observed. For Lake Tonlesap, there was no clear trend of rising daytime LST, but a slight albeit not significant nighttime decrease in LST was noted (Figure $4(\mathrm{j})$ ).

\section{[Insert Figure 4 about here]}

Figure 4: Inter-annual temperature variations of 10 selected typical large lakes from Asia. Please note that LWST is plotted on different scales for each lake.

\subsubsection{Typical lakes from Europe}

The inter-annual variations of 8 selected typical lakes across Europe during 2001-2015 are shown in Figure 5. An obvious increasing trend for nighttime LWST was observed in Lake Ladoga (Russia) $(\mathrm{y}=0.21 \mathrm{x}$ - 
428.07, $\mathrm{R}^{2}=0.36, \mathrm{P}=0.02$ ), while no definite trend was observed from daytime measurements $(\mathrm{y}=0.06 \mathrm{x}$ -122.44, $\mathrm{R}^{2}=0.1, \mathrm{P}=0.26$ ) (Figure 5(a)). Lake Onega, Vattern and Vanern are closely located (Figure 1), and exhibited very similar trend in LWST (Figure 5(b-d)), with highest and lowest annual temperatures recorded in 2007-2008 and 2011, respectively. A slight increase trend in LWST was noted for Lake Gevena (Figure $5(\mathrm{e})$ ). Likewise, Lake Neagh and Lake Kuybyshevskoye showed a slight trend in LWST increase, though not significant (Figure $5(\mathrm{f}-\mathrm{g})$ ). While the temporal variation in daytime LWST was not significant $(\mathrm{y}=0.03 \mathrm{x}$ $\left.-38.23, \mathrm{R}^{2}=0.11\right)$, Lake Bolsena showed a clear trend of increased nighttime LWST $\left(\mathrm{y}=0.05 \mathrm{x}-82.48, \mathrm{R}^{2}\right.$ $=0.38$; Figure $5(\mathrm{~h}))$ during the period of study.

\section{[Insert Figure 5 about here]}

Figure 5 : Inter-annual temperature variations of 8 selected typical large lakes from Europe. Please note that LWST is plotted on different scales for each lake.

\subsection{Ice-free line for Eurasian lakes}

Significant variability (S.D. $=187.9$ days) exist among Eurasian lakes with respect to the duration of the ice-free period, which can last between 24 and 365 days (Figure 6). At the continental scale, ice-free duration had a clear latitudinal pattern that matched the air temperature distribution. Lakes located in the boreal and tundra biomes, along with some lakes located at high elevation, exhibited short durations of ice-free period (24 to 168 days). Conversely, with the exception of those located at high elevation, lakes in the tropics were generally ice-free during the whole year. In general, lakes in the Tibetan Plateau had shorter ice-free durations compared to lakes located at lower elevation but at the same latitude. Everything else being the same, lakes with a large water volume generally had a longer ice-free duration than smaller lakes.

\section{[Insert Figure 6 about here]}

Figure 6: Distribution of ice-free duration for the large Eurasian lakes and reservoirs

\subsection{Regulating factors of lake surface temperature}

\subsubsection{Climatic zone and air temperature}

LWST varies according to climate zones (Figure 7). The temperature of most lakes in the dry climate zone varied between 17 and $31^{\circ} \mathrm{C}$, while for most lakes in the equatorial climatic zone LWST was between 23 and $27^{\circ} \mathrm{C}$. In the warm temperate climatic zone, LWST was in the range of 20 to $27^{\circ} \mathrm{C}$. In the cold temperate zone, for most lakes (620 lakes or $56.5 \%$ of Eurasian lakes) LWST was between -0.6 and $17{ }^{\circ} \mathrm{C}$. The average summer daytime LWST was $-0.71{ }^{\circ} \mathrm{C}$ in the polar climate zone.

The water temperature of lakes on the Tibetan Plateau are generally lower than in lakes at the same latitude but in other climatic regions. As shown in Table 1, the elevation of the three Tibetan lakes selected was $>4000$ $\mathrm{m}$, while the elevation of the three selected lakes in the Indo-Pakistani region was below $600 \mathrm{~m}$ (although at the same latitude). So, lakes elevation is a critical factor explaining difference in LWST. Based on our results, for every 100 meters increase in elevation, the LWST drops by about $0.6{ }^{\circ} \mathrm{C}$. The higher the altitude, the lower the lake water surface temperature.

All of the large water bodies in the South Asian subcontinent are man-made water reservoirs (Figure 7). In the Deccan Plateau (India), the altitude of the three selected reservoirs exhibiting highest and lowest LWST was between $425-519 \mathrm{~m}$. Land use type in the watersheds surrounding these reservoirs was generally similar (paddy field). Water depth was also similar (Table 1). So, the key difference among these three reservoirs was their climatic zones location. Therefore, the main driving factor of LWST in the South Asian subcontinent is climate zone, rather than lake morphometric characteristics.

Regression models were generated between in-situ air temperature and lakes LWST derived from MODIS to examine relationship between these variables (Figure 8). Positive relationships were found for daytime, nighttime and the daily mean air temperature.

\section{[Insert Figure 7 about here]}


Figure 7: Average lake water surface temperature (LWST) across climatic zones of Eurasia during the summer of 2015. Inside the red frames are the lakes of the Tibetan Plateau (a) and South Asian subcontinent (b). Keys to Koppen climatic zone classification: $\mathrm{A}=$ equatorial; $\mathrm{B}=$ Arid; $\mathrm{C}=$ warm temperate; $\mathrm{D}=$ snow climate; $\mathrm{E}=$ polar climate. Sub-categories for precipitation (second letter): $\mathrm{W}=\operatorname{desert} ; \mathrm{S}=$ steppe; $\mathrm{f}=$ fully humid; $\mathrm{m}=$ monsoonal; $\mathrm{s}=$ dry summer; $\mathrm{w}=$ dry winter. Subcategories for temperature (third letter): $\mathrm{a}=$ hot summer; $\mathrm{b}=$ warm summer; $\mathrm{c}=\mathrm{cool}$ summer; $\mathrm{d}=$ extremely continental; $\mathrm{h}=$ hot steppe; $\mathrm{k}=$ cold steppe.

\section{[Insert Figure 8 about here]}

Figure 8: Relationships between lake water surface temperature (LWST) and air temperature during the daytime (a) and nighttime (b).

Table 1: Basic information about typical lakes in the Tibetan Plateau (a) and South Asian subcontinent (b).

\begin{tabular}{llllll}
\hline & Lake name & CT & A & ASL & T \\
\hline (a) & Siling Co & Dwc VTH & 2,391 & 4,557 & 2.25 \\
MapamYumco & Dwb & 418 & 4,568 & -1.77 \\
Dogze Co & Dwc & 253 & 4,469 & 1.46 \\
Bias & Cwa & 301 & 429 & 19.22 \\
Mangera Dam & Cwa & 166 & 340 & 19.65 \\
Gowind Lake & Cwa & 137 & 517 & 20.45 \\
(b) & Ujani & BSh & 220 & 479 & 24.58 \\
Jayak & BSh & 275 & 457 & 22.14 \\
Naray & BSh & 90 & 488 & 23.18 \\
Majal & Aw & 47 & 426 & 20.72 \\
Nizam & Aw & 109 & 424 & 20.3 \\
Singur & Aw & 105 & 519 & 20.86 \\
\hline
\end{tabular}

CT: Climate Type; A: Area $\left(\mathrm{km}^{2}\right)$; ASL: elevation above sea level $(\mathrm{m})$; T: Annual average night temperature of lake waters $\left({ }^{\circ} \mathrm{C}\right)$.

\subsubsection{Lake area versus lake depth}

Area, depth and volume of lakes have strong impact on LWST (Figure 3, Table 1). Of the lakes investigated, Lake Tonlesap (Cambodia) exhibited the highest temperature (max: $26.87^{\circ} \mathrm{C}$ ); it is the shallowest of the lakes (around $12 \mathrm{~m}$ deep) and is located at the lowest elevation $(4 \mathrm{~m})$ (Table 2). A previous study has suggested that the annual heat budget of lakes is strongly dependent on mean depth because a deeper water column corresponds to a larger heat storage capacity (Gorham, 1964). That study further indicated a strong relationship between heat budget and lake water volume (semi-logarithmic scale) (Gorham, 1964). For deep and large lakes, more energy is needed to raise lake water temperature by one unit. Thus, less temporal variation in LWST was observed with the very large lakes, e.g., Baikal, Onega and Issyk (Figure 4 and Figure 5; Table 1). A similar line of reasoning can be advanced to explain the lower DTD values for lakes with large water volume. Lake Baikal showed slightly higher variability and DTDs than Lake Van (Eastern Turkey), but the difference was insignificant. Besides water volume, other factors (e.g., the ratio of area to mean depth, and shoreline characteristics) may have contributed to difference in LWST variability and DTDs (Leblanc, Akbarzadeh, Andrews, Lu, \& Golding, 2011), and future investigations should determine the extent of these contributions.

Table 2: Information about selected typical large Eurasia lakes

\begin{tabular}{lllllllll}
\hline & Water Depth $(\max )$ & Area & DT & NT & DTD & Continent & Latitude & Water Storage \\
\hline Bolsena & 151 & 114 & 16.44 & 14.47 & 1.98 & EU & 42.60 & 9
\end{tabular}




\begin{tabular}{lllllllll}
\hline & Water Depth $(\max )$ & Area & DT & NT & DTD & Continent & Latitude & Water Storage \\
\hline Neagh & 25 & 380 & 9.02 & 8.37 & 0.65 & EU & 54.62 & 4 \\
Geneva & 309.7 & 580 & 13.01 & 12.13 & 0.88 & EU & 46.46 & 89 \\
Khar_Us & 4.5 & 1194 & 4.11 & 1.51 & 2.60 & AS & 48.06 & 3 \\
Vattern & 128 & 1890 & 7.77 & 7.19 & 0.58 & EU & 58.60 & 74 \\
Tonlesap & 12 & 2570 & 26.87 & 26.31 & 0.56 & AS & 12.81 & 40 \\
Uvs & 10 & 3422 & 1.19 & -2.14 & 3.33 & AS & 50.30 & 40 \\
Van & 451 & 3538 & 13.08 & 12.18 & 0.90 & AS & 38.63 & 607 \\
Khanka & 6.5 & 4088 & 5.23 & 2.91 & 2.33 & AS & 45.09 & 18 \\
Taymyr & 26 & 4200 & -12.62 & -14.58 & 1.96 & AS & 74.40 & 13 \\
Kuybyshevskoye & 41 & 5003 & 5.15 & 3.03 & 2.12 & EU & 55.29 & 57 \\
Vanern & 106 & 5650 & 7.74 & 7.23 & 0.51 & EU & 59.06 & 153 \\
Issyk & 668 & 6259 & 11.20 & 10.42 & 0.77 & AS & 42.42 & 1690 \\
Onega & 120 & 9608 & 3.37 & 2.80 & 0.57 & EU & 61.65 & 280 \\
Balkhash & 25.6 & 17459 & 7.70 & 5.70 & 2.00 & AS & 46.30 & 106 \\
Ladoga & 230 & 17539 & 5.40 & 5.25 & 0.15 & EU & 60.77 & 837 \\
Baikal & 1637 & 31925 & 1.69 & -0.44 & 2.12 & AS & 54.20 & 23000 \\
Qinghai & 21.3 & 4340 & 5.98 & 5.13 & 0.85 & AS & 36.96 & 739 \\
\hline
\end{tabular}

Water depth: maximum water depth $(\mathrm{m})$, Area: lake area at the surface $\left(\mathrm{km}^{2}\right)$, DT: daytime temperature $\left({ }^{\circ} \mathrm{C}\right)$, NT: nighttime temperature $\left({ }^{\circ} \mathrm{C}\right)$, DTD: diurnal temperature difference $\left({ }^{\circ} \mathrm{C}\right)$, Latitude (degree), Water storage $\left(\mathrm{km}^{3}\right)$

\subsubsection{Ice cover trend and salinity}

On a continental scale, lakes at high latitudes and high altitudes tend to have low LWST and short ice-free duration (Figure 6 and Table 3). Lakes Niagame and Kungasalakh, located near the Arctic Circle, exhibited much shorter ice-free time (average: 56 and 64 days, respectively) compared to Lake Eloygytgyn and Yambuto in eastern Siberia (128 days and 136 days, respectively). Since these lakes are found at similar elevations and are located in the same climatic zone, water chemistry could be a reason for the difference in ice-free duration. It is well known that increased salinity of lake waters can increase ice formation temperature, thus an extension in ice-free duration should be expected for lakes with high salinity (Wang \& Dou, 1998). The merit of that contention cannot be determined by the data presented in this study, but it does underscore the need to further investigate how salinity could affect the dynamics of ice formation, the duration of the ice-free period in lakes, and ultimately the response of water temperature in these water bodies to a warming global climate.

Table 3: The top ten lakes (from a set of 1,098 lakes) with the lowest water surface temperature across Eurasia

\begin{tabular}{lllllllll}
\hline Lowest T & Climatic Zone & Continent & DT & NT & Average & DTD & Ice free day & ASL \\
\hline Ilergytgyn & Tundra & Asia & -9.29 & -9.46 & -9.38 & 0.17 & 96 & 9 \\
Yambuto & Tundra & Asia & -9.33 & -10.39 & -9.86 & 1.06 & 136 & 2 \\
Bustakh & Tundra & Asia & -9.52 & -10.79 & -10.16 & 1.27 & 96 & 1 \\
Eloygytgyn & Tundra & Asia & -9.66 & -11.82 & -10.74 & 2.16 & 128 & 497 \\
Kungasalakh & Tundra & Asia & -9.99 & -12.05 & -11.02 & 2.06 & 64 & 77 \\
Bol'shoye Morskoye & Tundra & Asia & -10.1 & -10.16 & -10.13 & 0.06 & 104 & 10 \\
Portnyagino & Tundra & Asia & -10.16 & -12.14 & -11.15 & 1.98 & 88 & 55 \\
Chukochye & Tundra & Asia & -10.5 & -10.88 & -10.69 & 0.38 & 104 & 1 \\
Niagame & Tundra & Asia & -10.52 & -9.43 & -9.98 & 1.09 & 56 & 65 \\
Taymyr & Tundra & Asia & -12.6 & -14.58 & -13.59 & 1.98 & 104 & 46 \\
\hline
\end{tabular}


DT: daytime temperature $\left({ }^{\circ} \mathrm{C}\right), \mathrm{NT}$ : nighttime temperature $\left({ }^{\circ} \mathrm{C}\right)$, DTD: diurnal temperature difference $\left({ }^{\circ} \mathrm{C}\right)$. ASL: elevation above sea level (m).

\section{Conclusions}

The study demonstrated the utility of MODIS LST products to monitor the spatial, diurnal, seasonal, and annual variations of lakes water surface temperature (LWST) across Eurasia where long-term insitumeasurements are very limited. In particular, this is an effective approach for monitoring LWST in some of the wild, inaccessible and protected areas in high latitude regions of the word. The inter-annual and intra-annual variations of LWST across Eurasia were derived from 11,978 maps of daytime and nighttime 8day composite MODIS LST products during the period 2001-2015. Lakes in high latitude regions, especially those situated in the boreal or the Taiga biome displayed low LWST. Lakes in the Tibetan Plateau also exhibited low LWST. However, the LWST pattern in nighttime showed a more homogeneous distribution, and the pattern mostly resembled that of air temperature at Eurasian scale. Large spatial variations of DTDs were observed for large lakes in Eurasia. Small variations in DTDs were measured in high latitude lakes, and also in lakes situated in the tropical rainforest region. Several factors, e.g., lake depth and area (volume), altitude, and water source, may have contributed to the spatiotemporal variations in LWST. The shallow lakes showed a rapid response of LWST to solar and atmospheric forcing, while in the large deep lakes, the response time was much slower. Finally, it should be noted that LWST and ice-free duration can be influenced by water salinity and ground water input, but these factors were not considered in the present study. Further investigation is thus needed to assess the impact of these factors on the thermal dynamics of large water bodies across the Eurasian continent.

\section{References}

Adrian, R., O’Reilly, C. M., Zagarese, H., Baines, S. B., Hessen, D. O., Keller, W., .. \& Weyhenmeyer, G. A. (2009). Lakes as sentinels of climate change. Limnology and oceanography , 54 (6part2), 2283-2297. https://doi.org/10.4319/lo.2009.54.6_part_2.2283.

Deo, R. C., \& Şahin, M. (2017). Forecasting long-term global solar radiation with an ANN algorithm coupled with satellite-derived (MODIS) land surface temperature (LST) for regional locations in Queensland. Renewable and Sustainable Energy Reviews, 72 , 828-848.

https://doi.org/10.1016/j.rser.2017.01.114.

Dörnhöfer, K., \& Oppelt, N. (2016). Remote sensing for lake research and monitoring-Recent advances. Ecological Indicators , 64, 105-122.https://doi.org/10.1016/j.ecolind.2015.12.009.

Downing, J. A., Prairie, Y. T., Cole, J. J., Duarte, C. M., Tranvik, L. J., Striegl, R. G., Middelburg, J. J. (2006). The global abundance and size distribution of lakes, ponds, and impoundments. Limnology and Oceanography . 51(5), 2388-2397.https://doi.org/10.4319/lo.2006.51.5.2388.

Gorham, E. (1964). MORPHOMETRIC CONTROL OF ANNUAL HEAT BUDGETS IN TEMPERATE LAKES 1. Limnology and Oceanography, 9 (4), 525-529. https://doi.org/10.4319/lo.1964.9.4.0525.

Hook, S. J., Vaughan, R. G., Tonooka, H., \& Schladow, S. G. (2007). Absolute radiometric in-flight validation of mid infrared and thermal infrared data from ASTER and MODIS on the Terra spacecraft using the Lake Tahoe, CA/NV, USA, automated validation site. IEEE Transactions on Geoscience and Remote Sensing , 45 (6), 1798-1807. https://doi.org/10.1109/TGRS.2007.894564.

IPCC (2014). "Climate Change 2014: Synthesis Report," in Proceedings of the Contribution of Working Groups I, II and III to the Fifth Assessment Report of the Intergovernmental Panel on Climate Change, eds Core Writing Team, R. K. Pachauri, and L. A. Meyer (Geneva: IPCC), 151. 
Ke, L., \& Song, C. (2014). Remotely sensed surface temperature variation of an inland saline lake over the central Qinghai-Tibet Plateau. ISPRS journal of photogrammetry and remote sensing , 98 , 157167.https://doi.org/10.1016/j.isprsjprs.2014.09.00\%.

Kraemer, B. M., Mehner, T., \& Adrian, R. (2017). Reconciling the opposing effects of warming on phytoplankton biomass in 188 large lakes. Scientific reports , 7(1), 10762.

Leblanc, J., Akbarzadeh, A., Andrews, J., Lu, H., \& Golding, P. (2011). Heat extraction methods from salinity-gradient solar ponds and introduction of a novel system of heat extraction for improved efficiency. Solar Energy , 85 (12), 3103-3142.https://doi.org/10.1016/j.solener.2010.06.005.

Lehner, B., \& Döll, P. (2004). Development and validation of a global database of lakes, reservoirs and wetlands. Journal of Hydrology, 296 (1-4), 1-22.https://doi.org/10.1016/j.jhydrol.2004.03.028.

Li, R., Chen, Q., Zhang, X., \& Recknagel, F. (2015). Effects of temperature and macronutrients on phytoplankton communities across three largely different lakes identified by a time-space trade-off approach. Ecological informatics , 29 , 174-181.https://doi.org/10.1016/j.ecoinf.2014.09.004.

Lyons, E. A., \& Sheng, Y. (2018). Laketime: Automated seasonal scene selection for global lake mapping using landsat etm+ and oli. Remote Sensing , 10 (1), 54.https://doi.org/10.3390/rs10010054.

Ma, N., Szilagyi, J., Niu, G. Y., Zhang, Y., Zhang, T., Wang, B., \& Wu, Y. (2016). Evaporation variability of Nam Co Lake in the Tibetan Plateau and its role in recent rapid lake expansion. Journal of hydrology , 537, 27-35. https: // doi.org/10.1016/j. jhydrol.2016.03.030.

Meybeck, M. (1995). Global distribution of lakes. In Physics and chemistry of lakes (pp. 1-35). Springer, Berlin, Heidelberg. https://doi.org/10.1007/978-3-642-85132-2_1.

Moukomla, S., \& Blanken, P. (2016). Remote sensing of the North American Laurentian Great Lakes' surface temperature. Remote Sensing , 8 (4), 286.https://doi.org/10.3390/rs8040286.

NASA Land Processes Distributed Active Archive Center (LP DAAC) (2001) MODIS 11A2. USGS/Earth Resources Observation and Science (EROS) Center, Sioux Falls, South Dakota.

O'Reilly, C. M., Sharma, S., Gray, D. K., Hampton, S. E., Read, J. S., Rowley, R. J., .. \& \& Weyhenmeyer, G. A. (2015). Rapid and highly variable warming of lake surface waters around the globe. Geophysical Research Letters , 42 (24), 10-773. https://doi.org/10.1002/2015GL066235.

Parastatidis, D., Mitraka, Z., Chrysoulakis, N., Abrams, M., 2017. Online global land surface temperature estimation from Landsat. Remote. Sens Basel. 9(12), 1208. https: // doi. org/10. 3390/rs9121208.

Parastatidis, D., Mitraka, Z., Chrysoulakis, N., \& Abrams, M. (2017). Online global land surface temperature estimation from landsat. Remote Sensing, 9 (12), 1208.

https://doi.org/10.1007/s10201-016-0481-z.

Schmidt, S. R., Gerten, D., Hintze, T., Lischeid, G., Livingstone, D. M., \& Adrian, R. (2018). Temporal and spatial scales of water temperature variability as an indicator for mixing in a polymictic lake. Inland Waters , 8 (1), 82-95.https://doi.org/10.1080/20442041.2018.142906\%.

Sheng, Y., Song, C., Wang, J., Lyons, E. A., Knox, B. R., Cox, J. S., \& Gao, F. (2016). Representative lake water extent mapping at continental scales using multi-temporal Landsat-8 imagery. Remote Sensing of Environment, 185 , 129-141. https://doi.org/10.1016/j.rse.2015.12.041.

Song, K., Wang, M., Du, J., Yuan, Y., Ma, J., Wang, M., \& Mu, G. (2016). Spatiotemporal variations of lake surface temperature across the Tibetan Plateau using MODIS LST product. Remote Sensing , 8 (10), 854. https: // doi. org/10. 3390/rs8100854. 
Trumpickas, J., Shuter, B. J., Minns, C. K., \& Cyr, H. (2015). Characterizing patterns of nearshore water temperature variation in the North American Great Lakes and assessing sensitivities to climate change. Journal of Great Lakes Research , 41 (1), 53-64.https://doi.org/10.1016/j.jglr.2014.11.024.

Wang, S. M., \& Dou, H. S. (1998). Lakes in China . Science professional publishing.

Wetzel, R. G. (2001). Limnology: lake and river ecosystems . gulf professional publishing.

Winslow, L. A., Read, J. S., Hansen, G. J., Rose, K. C., \& Robertson, D. M. (2017). Seasonality of change: Summer warming rates do not fully represent effects of climate change on lake temperatures. Limnology and Oceanography ,62 (5), 2168-2178.

https://doi.org/10.1002/lno.1055\%.

Woolway, R. I., Verburg, P., Lenters, J. D., Merchant, C. J., Hamilton, D. P., Brookes, J., ... \& Laas, A. (2018). Geographic and temporal variations in turbulent heat loss from lakes: A global analysis across 45 lakes. Limnology and Oceanography, 63 (6), 2436-2449. https:// doi. org/10. 1002/ Ino. 10950.

Yuan, Y., Zeng, G., Liang, J., Huang, L., Hua, S., Li, F., . . \& He, Y. (2015). Variation of water level in Dongting Lake over a 50-year period: Implications for the impacts of anthropogenic and climatic factors. Journal of Hydrology , 525 , 450-456.https://doi.org/10.1016/j.jhydrol.2015.04.010.

Zhang, G., Yao, T., Xie, H., Qin, J., Ye, Q., Dai, Y., \& Guo, R. (2014). Estimating surface temperature changes of lakes in the Tibetan Plateau using MODIS LST data. Journal of Geophysical Research: Atmospheres , 119 (14), 8552-8567. https://doi.org/10.1002/2014JD021615.

Zhang, G., Xie, H., Kang, S., Yi, D., \& Ackley, S. F. (2011). Monitoring lake level changes on the Tibetan Plateau using ICESat altimetry data (2003-2009). Remote Sensing of Environment , 115 (7), 17331742.https://doi.org/10.1016/j.rse.2011.03.005.

Zhong, Y., Notaro, M., \& Vavrus, S. J. (2019). Spatially variable warming of the Laurentian Great Lakes: an interaction of bathymetry and climate. Climate Dynamics , 52 (9-10), 58335848.https://doi.org/10.1007/s00382-018-4481-z.

\section{Acknowledgments:}

Thanks are extended to the NASA for providing free MODIS LST products.

\section{Hosted file}

Tables.docx available at https://authorea.com/users/290342/articles/417051-monitoring-ofwater-surface-temperature-of-eurasian-large-lakes-using-modis-lst-product 

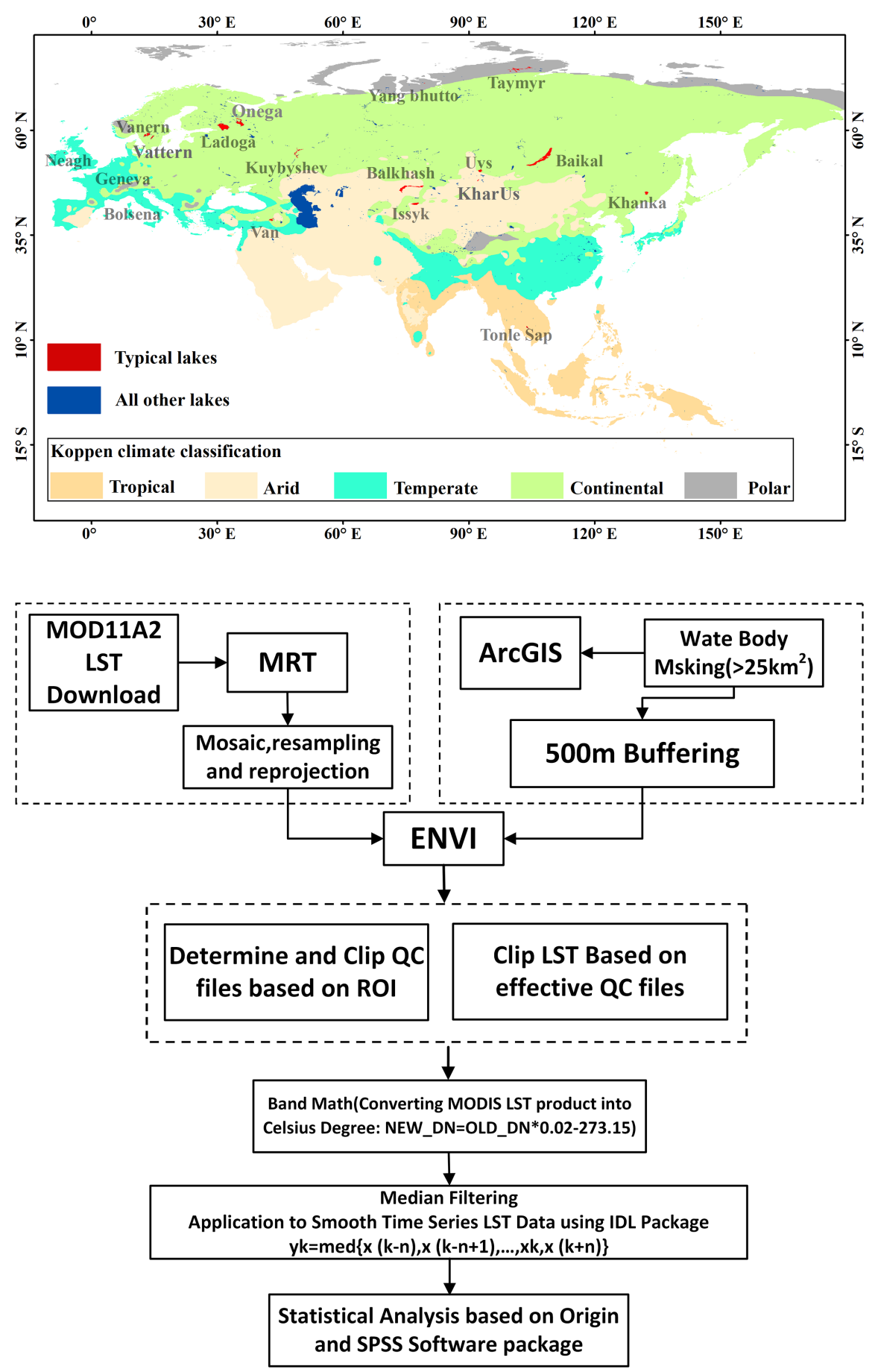

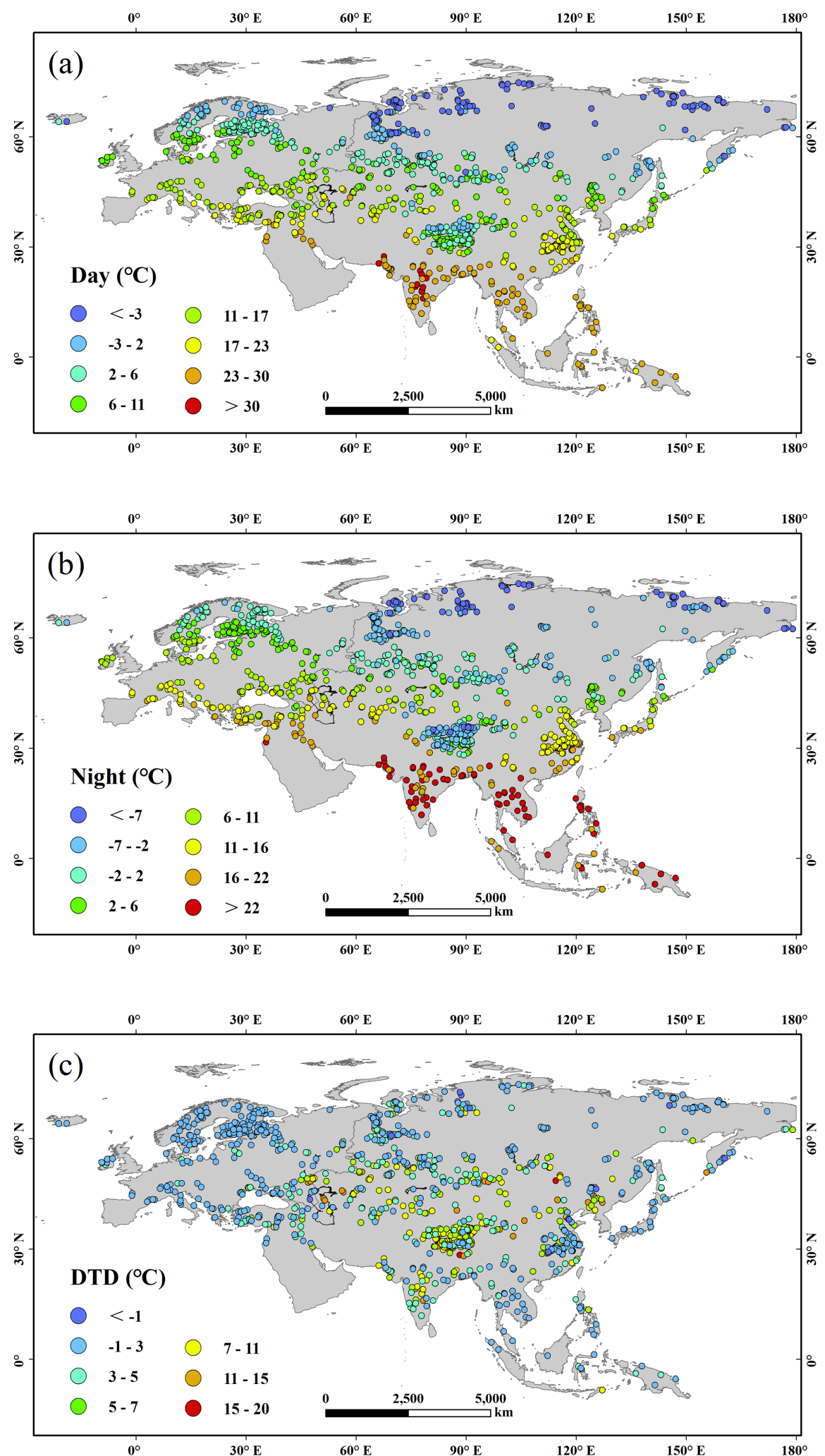

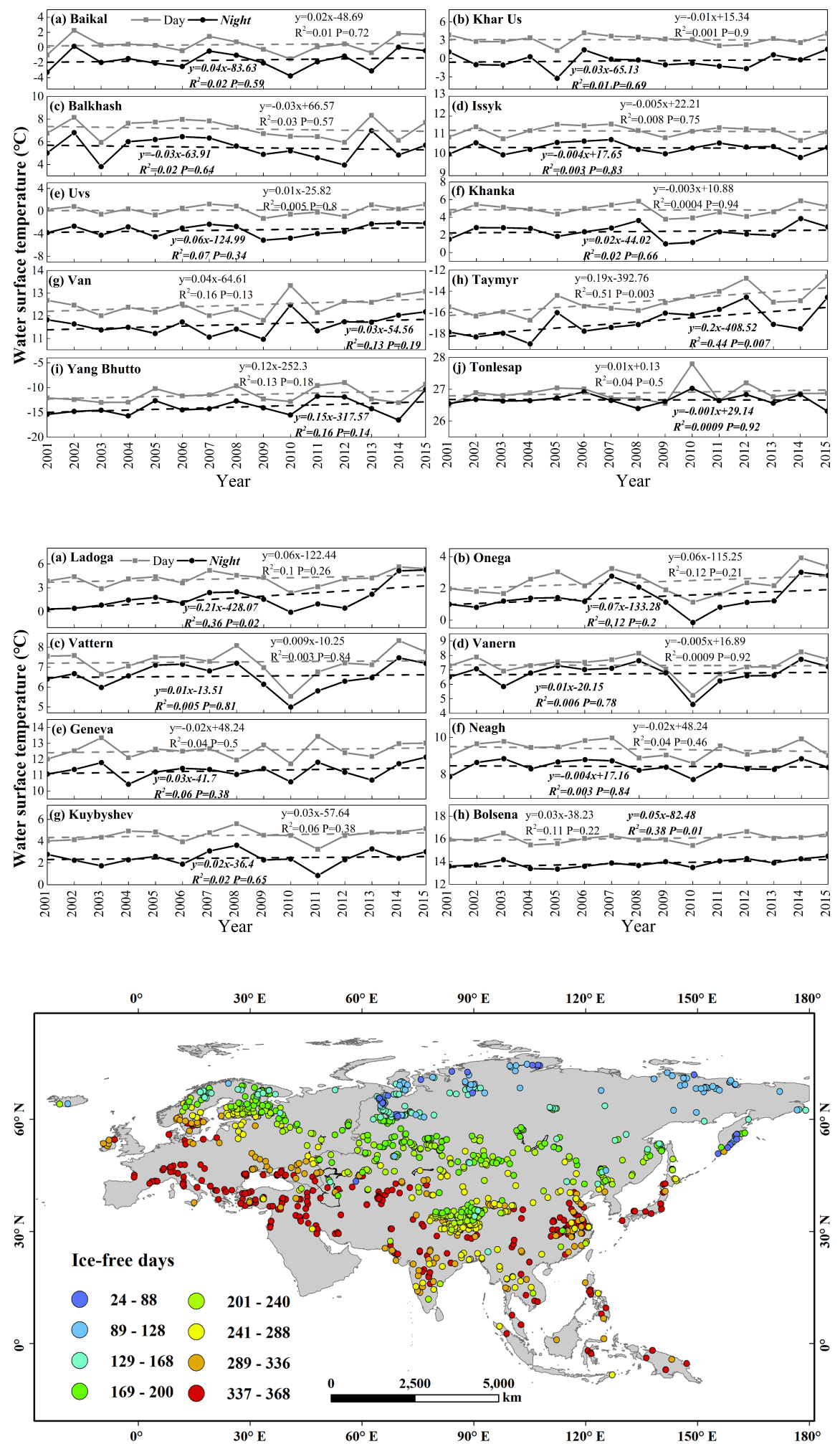

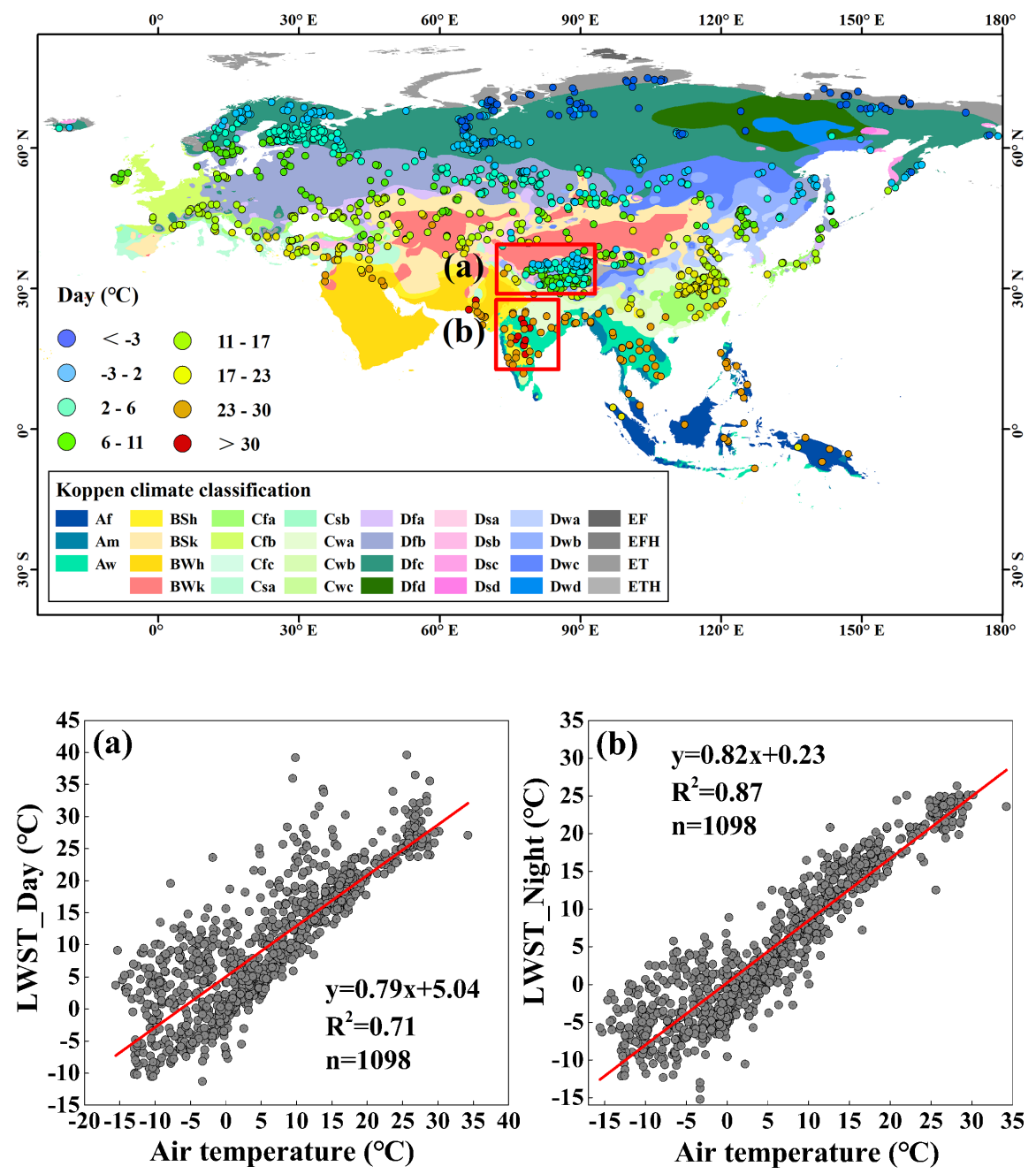